\title{
STRATEGI PENGEMBANGAN BISNIS PT. ADHI PERSADA PROPERTI
}

\author{
BUSINESS DEVELOPMENT STRATEGY OF PT. ADHI PERSADA PROPERTI
}

\author{
Muhammad Irdy Eka Mahendra*)1, Mukhamad Najib ${ }^{* *)}$, dan Kirbrandoko ${ }^{* * *}$ \\ *) Sekolah Bisnis, IPB University \\ Jl. Raya Pajajaran, Bogor 16151, Indonesia \\ **) Departemen Manajemen, Fakultas Ekonomi dan Manajemen, IPB University \\ Jl. Agatis Kampus IPB Dramaga, Bogor 16680, Indonesia \\ $\left.{ }^{* * *}\right)$ Universitas Ibn Khaldun Bogor \\ Jl. K.H. Sholeh Iskandar Km. 2, Tanah Sereal, Bogor, 16164, Indonesia
}

\begin{abstract}
The property industry is a highly developed industry in Indonesia. Several factors such as infrastructure development (toll roads, railroads, public transportation, etc.), the need for shelter, increasing population, etc. PT. Adhi Persada Properti (APP) is a subsidiary of PT. Adhi Karya (Adhi) which delayed the purchase of property in the industry (apartments, housing, etc.). The objectives of this study are internal, external, key success factors in the property industry and the Business Model Canvas to identify business models with the results of long-term and short-term strategies for APP to improve competitiveness in the property industry. Data analysis methods and methods used are PEST Analysis, Focus Group Discussions, and Business Model Canvas. The results show that APP's main threat as an apartment and housing developer is in terms of regulations. Opportunities that can be utilized by APP through external analysis are the level of public purchasing power, economic growth and advancement in information technology. The level of purchasing power and economic growth is more influential on the sale of APP products. The BMC results of identification of each section in APP can be clearly mapped, which parts should be developed and which are maintained as they are at present.
\end{abstract}

Keywords: property, external and internal issue, business model canvas, strategic planning

\begin{abstract}
Abstrak: Industri properti merupakan industri yang sangat berkembang di Indonesia. Beberapa faktor seperti pembangunan infrastruktur (jalan tol, rel kereta, transprotasi umum, dll), kebutuhuhan akan tempat tinggal, kenaikan jumlah penduduk, dll. PT. Adhi Persada Properti (APP) adalah anak perusahaan dari PT. Adhi Karya (Adhi) yang berfokus pada industry properti (apartemen, perumahan, dll) mengalami penurunan penjualan dalam 3 tahun terakhir. Tujuan penelitian ini adalah mengidentifikasi faktor internal, eksternal, key success factor di industry property dan Bisnis Model Kanvas untuk mengidentifkasi model bisnis dengan hasil sebuah strategi jangka panjang dan jangka pendek untuk APP untuk meningkatkan daya saing di industri properti. Metode dan analisis data yang digunakan adalah PEST Analysis, Focus Group Discussion, dan SWOT Business Model Canvas. Hasil menunjukkan ancaman utama APP sebagai developer apartemen dan perumahan adalah dari sisi regulasi/peraturan. Peluang yang bisa dimanfaatkan APP melalui analisis eksternal adalah tingkat daya beli masyarakat, pertumbuhan ekonomi dan kemajuan teknologi informasi. Tingkat daya beli dan pertumbuhan ekonomi lebih berpengaruh terhadap penjualan produk APP. Hasil BMC identifikasi masing-masing bagian di APP dapat terpetakan dengan jelas, bagian mana yang harus di kembangkan dan mana yang dipertahankan sebagaimana adanya saat ini.
\end{abstract}

Kata kunci: properti, masalah eksternal dan internal, kanvas model bisnis, perencanaan strategis

\footnotetext{
${ }^{1}$ Corresponding author:

Email:muh.irdy@gmail.com
} 


\section{PENDAHULUAN}

Industri properti adalah salah satu sektor industri yang sangat penting bagi pertumbuhan perekonomian Indonesia, karena banyaknya industri turunan yang ada di dalam sektor tersebut, termasuk diantaranya adalah penyedia material bahan baku, pengolahan bahan baku hingga menjadi bahan siap pakai seperti semen dan beton, dekorasi interior dan eksterior, industri furnitur,dll . Kebijakan pemerintah dalam periode 2014-2019 yang dicanangkan dalam RJPMN (Rencana Pemerintah Jangka Menengah Nasional) menggambarkan bahwa pembangunan infrastruktur adalah prioritas, dengan penanaman modal sebesar 5.500 Triliun rupiah yang terbagi ke dalam beberapa proyek yang erat kaitannya dengan sektor properti seperti pembangunan jalan, jalur kereta api, transportasi antar kota, bandar udara, juga transportasi laut.

Tren yang sedang terjadi di Indonesia saat ini khususnya di kota-kota besar adalah produk properti berupa apartemen dan perumahan bawah justru semakin diminati (Real Estate Indonesia, 2017). Terbukti hingga bulan Mei 2018 tercatat ada 600 proyek properti yang dikembangkan dan $44,7 \%$ diantaranya adalah apartemen dan perumahan menengah-atas.Bisnis Indonesia (2012) memperikarakan bahwa dalam jangka waktu kurang lebih 12 tahun properti baik itu apartemen maupun perumahah masih akan mendominasi. Bisnis Indonesia merujuk pada surveiharga properti residensial yang dilakukan oleh Bank Indonesia (BI) terhadap kebutuhan properti. Dimana berdasarkan IHPR (Indeks Harga Properti Residence) pada triwulan I-2018 secara triwulanan meningkat sebesar 1,42\%. Secara tahunan indeks harga properti juga meningkat $3,05 \%$. Ini memberikan sinyal bahwa pasar properti masih menjadi pilihan investasi jangka panjang yang cukup menjanjikan.

Saat ini APP sedang memanfaatkan peluang atas proyek pembangunan jalur LRT yang rencananya akan selesai pada tahun 2019, dengan pengembangan apartemen di Bekasi yang letaknya persis berada di ujung stasiun LRT. Apartemen yang sudah dimulai pembangunannya pada tahun 2013 dan sampai saat ini sudah mencapai $80 \%$ tersebut menerapkan konsep mix used dimana mall, ruko dan apartemen nantinya akan terhubung menjadi satu. Hal ini sejalan dengan strategi perusahaan yang menerapkan konsep TOD (Transit Oriented
Development) yang membangun apartemen yang akan terhubung langsung dengan pusat transportasi, seperti contohnya stasiun LRT ini. Perusahaan meyakini bahwa hal itu akan menjadi salahsatu nilai jual (selling point) bagi produknya, terkait dengan kemudahan akses ke transportasi masal. Mempunyai berbagai keunggulan dalam nilai jual produk khususnya dalam segmen apartemen kampus dan apartemen di sepanjang jalur LRT tidak serta merta menjadikan APP aman dari persaingan. Pada tahun 2018 ini justru perusahaan sedang menghadapi penurunan penjualan hingga mencapai 35-40\%. Grafik rata-rata penjulaan perbulan dari tahun 2014-2018 pada Gambar 1.

Faktor lainnya yang membuat PT. Adhi Persada Properti (APP) mengalami penurunan daya saing adalah penilaian dari Pefindo (Pemeringkat Efek Indonesia), dimana dalam penilaianya APP mengalami penurunan dari tahun 2017 ke 2018 dengan catatan dari tahun 2016 ke 2017 mengalami stagnan. Situasi ini banyak dipengaruhi oleh faktor eksternal perusahaan seperti pertumbuhan ekonomi yang lambat, tingkat suku bunga dan inflasi, tidak stabilnya nilai tukar rupiah, tingkat suku bunga kredit yang dinilai mahal, menurunnya dayabeli masyarakat khususnya pada properti dan situasi politik yang bertepatan dengan siklus pemilu lima tahunan.

Pada dasarnya industri properti pada produk apartemen memiliki beberapa tujuan pemasaran, yaitu ketertarikan pembeli baik untuk dipakai sendiri maupun memanfaatkannya sebagai investasi. Dalam hal ini tentunya apartemen dengan tipe atau spesifikasi kecil, murah serta dekat dengan akses ke mass rapid transit (MRT) dan light rapid transit (LRT) akan banyak mendapatkan pangsa pasar yang lebih baik (Prasongko, 2018).

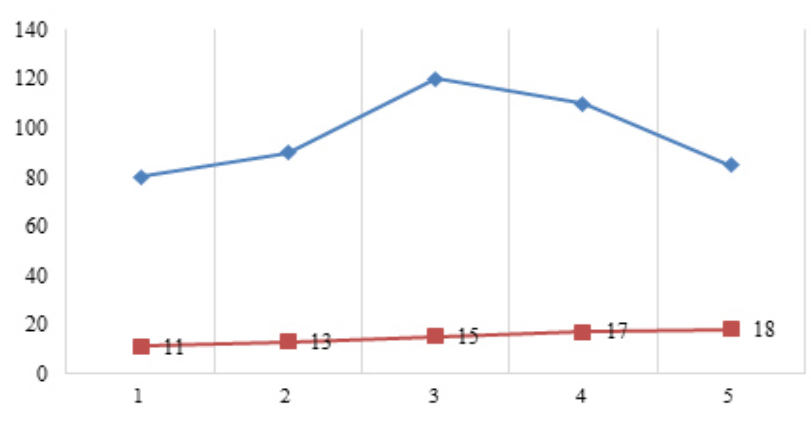

Gambar 1. Grafik rata-rata penjulaan perbulan dari tahun 2014-2018 
Adanya tantangan yang sedang dihadapi APP harus ditanggapi dengan strategi-strategi yang lebih baik. Menurut Giesen et al. (2007), cara perusahaan dalam mengatasi perubahan dan persaingan adalah dengan inovasi model bisnis sebagai jalan untuk meningkatkan daya saing dan meningkatkan pertumbuhan perusahaan.

Beberapa penelitian terdahulu yang telah dilakukan antara lain Alfanur (2014) yang berjudul Analisis Inovasi Model Bisnis mengunakan pendekatan Business Model Canvas (BMC). Hasil menunjukkan Bebek Garang memiliki beberapa blok yang memiliki ancaman yang tinggi, yaitu value proposition, cost structure, channels. Kekuatan Bebek Garang terletak pada revenue streams, value proposition, key partnership. Sedangkan, kelemahannya terletak pada Channels dan key activities. Selanjutnya, Prihandini (2018) melakukan penelitian Analisis strategi pengembangan bisnis real estate di PT Mekar Agung Sejahtera dengan pendekatan SWOT, BMC, Analisis Deskriptif. Hasil penelitian diperlukan strategi pengembangan yang lebih baik, perlunya menciptakan value proposition dengan lebih mengambangakan model bisnis kanvas yang dilakukan. Di sisi lain, Perdana (2014) melakukan penelitian analisis hubungan channel daengan costumer segment dengan pendekatan BMC. Strategi bisnis model canvas adalah pola non linear pada hubungan antara komponon channel dengan costumer segment dalam $\mathrm{BMC}$, yaitu segmen pelanggan price sensitive costumer dan insensitive.
Sebagai perusahaan yang sedang berkembang, tentunya APP membutuhkan model bisnis dan strategi alternatif yang lebih baik dan langkah-langkah penerapannya dalam jangka pendek maupun jangka panjang diharapkan mampu membantu APP meningkatkan daya saingnya di tengah kompetisi yang semakin ketat dan mengembalikan kinerjanya. Dengan hal tersebut, tujuan penelitian ini adalah menganalisis faktor Internal dan eksternal, menganalisis key success factor, merumuskan model bisnis, dan merumuskan strategi berdasarkan BMC.

\section{METODE PENELITIAN}

Penilitian dilakukan pada produk properti APP yang ada di daerah Jabodetabek. Penelitian dilakukan dengan metode deskriptif. Data yang digunakan adalah data primer dan data sekunder. Data primer diperoleh dari hasil observasi, studi literatur dan wawancara kepada beberapa pihak yang beraiktan dengan industri properti di dalam perusahaan maupun pihak ekstenal yang mengetahui kondisi perusahaan dan kondisi industri properti. Alat analisis yang digunakan antara lain PEST Analysis dan BMC yang selengkapnya pada Tabel 1. Kerangka pemikiran penelitian secara singkat dapat dilihat pada Gambar 1.

Tabel 1. Penjelasan metode analisis penelitian

\begin{tabular}{|c|c|c|c|}
\hline Tujuan Penelitian & Alat Analisis & Hasil & Responden \\
\hline $\begin{array}{l}\text { Menganalisis faktor Internal } \\
\text { dan Eksternal }\end{array}$ & $\begin{array}{l}\text { Wawancara, PEST Analysis, } \\
\text { Kuesioner (PEST Analysis) }\end{array}$ & $\begin{array}{l}\text { Faktor-faktor Internal dan } \\
\text { Eksternal }\end{array}$ & $\begin{array}{l}\text { Analisis Internal : Direktur } \\
\text { Pengembangan, VP } \\
\text { pengembangan, Manajer } \\
\text { Corporate Strategy, } \\
\text { Manajer Penjualan, dan VP } \\
\text { Penjualan. }\end{array}$ \\
\hline Analisis Key Success Factor & Wawancara, Studi Literatur & Key Success Factor Property & $\begin{array}{l}\text { VP Penjualan, VP } \\
\text { pengembangan, VP } \\
\text { Pengendalian dan VP } \\
\text { Keuangan }\end{array}$ \\
\hline Merumuskan Model Bisnis & $\begin{array}{l}\text { Focus Group Discussion, } \\
\text { Business Model Canvas }\end{array}$ & $\begin{array}{l}9 \text { Blok yang ada di dalam } \\
\text { BMC }\end{array}$ & $\begin{array}{l}\text { VP Penjualan, VP } \\
\text { pengembangan, VP } \\
\text { Pengendalian dan VP } \\
\text { Keuangan }\end{array}$ \\
\hline $\begin{array}{l}\text { Mermuskan strategi } \\
\text { berdasarkan BMC }\end{array}$ & Focus Group Discussion & Strategi pengembangan & \\
\hline
\end{tabular}




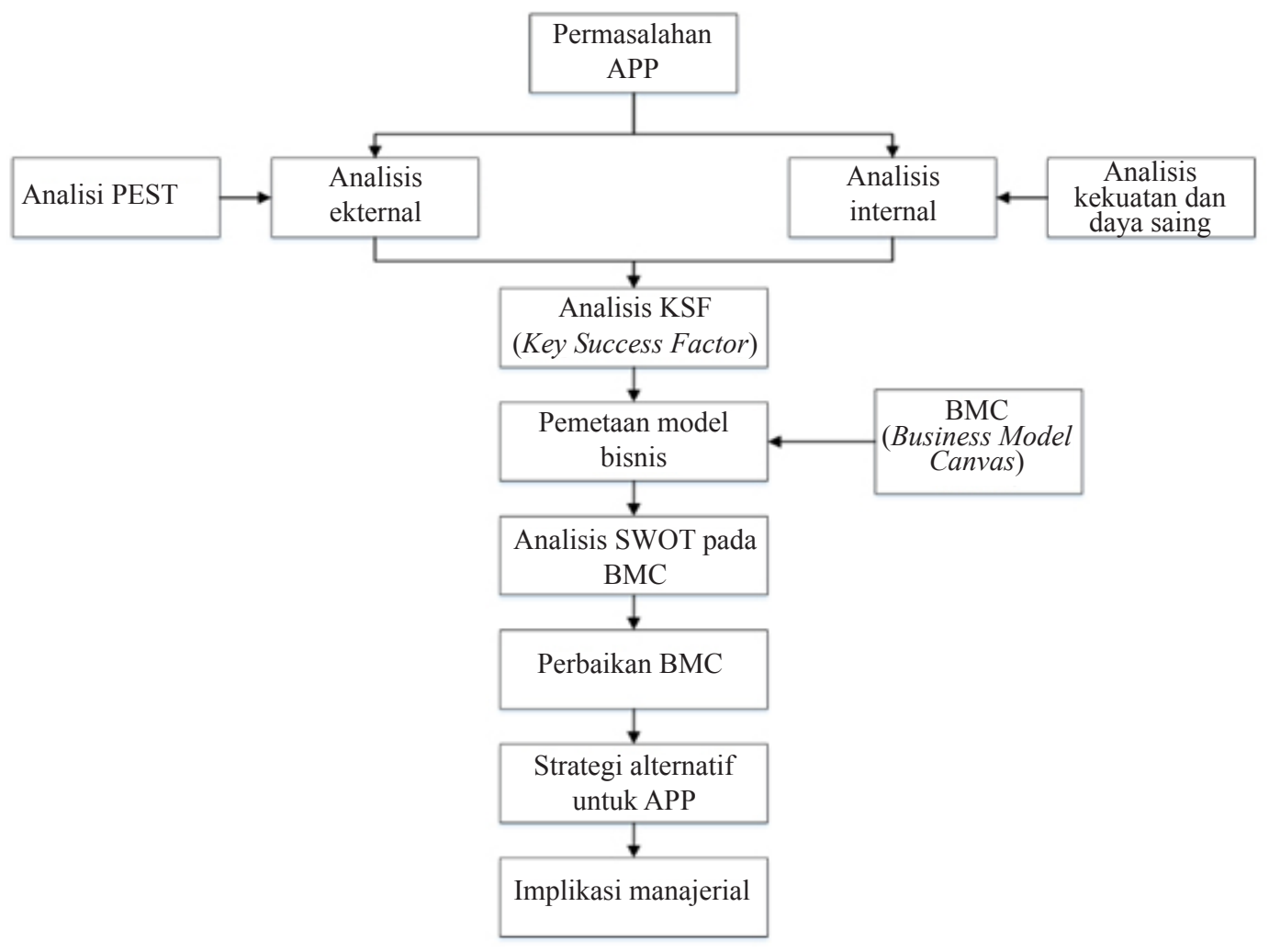

Gambar 2. Kerangka pemikiran penelitian

\section{HASIL}

\section{Gambaran Umum PT. Adhi Persada Properti}

PT. Adhi Persada Properti (APP) merupakan anak perusahaan dari PT. Adhi Karya (ADHI) yang bergerak dibidang konstruksi. Pada Tahun 1993 APP masih berupa unit usaha dari ADHI. Baru pada tahun 2002 APP menjadi anak perusahaan yang berfokus pada bidang properti dan real estate. Proyek TOD (Transit Oriented Development) yang pertama kali dikembangkan oleh APP berlokasi di ujung stasiun LRT yaitu di Bekasi Timur pada tahun 2013 dan sampai saat ini sudah terjual $85 \%$. Sampai saat ini APP sedang mengembangkan 21 proyek, dan pada tahun 2018 APP baru saja mengembangakan apartemen dengan kelas high-end pertamanya yang terletak dijalan Sinabung, Permata Hijau, Jakarta Selatan.

\section{Analisis Eksternal}

Berdasarkan bantuan alat uji terhadap analisis PEST dengan faktor-faktor eksternal dalam aspek politik, ekonomi, sosial, dan teknologi. Diperoleh bahwa dalam faktor ekonomi ada peluang yang bisa dimanfaatkan oleh APP, yaitu tingkat daya beli masyarakat dan pertumbungan ekonomi di Indonesia. Ancaman dalam faktor ekonomi bagi APP adalah kenaikan suku bunga pada KPR/KPA dan fluktuasi mata uang. Faktor politik menjadi ancaman yang cukup mempengaruhi proses bisnis dibidang properti. Adanya Pilkada serentak pada tahun 2018, Pilpres dan Pileg 2019 menjadi suatu batu sandungan bagi developer. Dengan adanya perubahan kepemimpinan, maka dari segi aspek regulasi pun akan berubah walaupun perubahan tersebut tidak terlalu signifikan. Faktor regulasi menjadi penghambat bagi developer karena hukum yang berlaku harus ditaati, ini menjadi penghambat apabila developer mempunyai cadangan lahan tapi terpenuhinya regulasi untuk mendirikan proyek properti disana atau bisa saja regulasinya membolehkan untuk membangun produk properti hanya saja dalam masala perizinan menjadi kendala bagi developer. Perubahan gaya hidup dan hubungan dengan masyarakat menjadi ancaman dalam faktor sosial. Perubahan gaya hidup menjadi ancaman karena produk properti yang didesign oleh APP mengikuti gaya hidup yang ada pada tahun tersebut sampai ke lima tahun mendatang, sementara masyarakat bisa saja merubah gaya hidupnya 1-2 tahun lebih cepat. Dalam aspek teknologi, perkembangan teknologi menjadi peluang bagi APP untuk dapat meningkatkan kegiatan bisinisnya. Pemanfaatan teknologi bisa dilakukan dengan memanfaatkan media social untuk publikasi perusahaan, pemanfaatan teknologi informasi untuk operasional dan juga penjualan produk. 


\section{Analisis Internal}

Masih dalam lingkup pemasaran dan penjualan, dalam lingkup produktifitas tenaga penjual APP terdapat dua proyek APP yang masuk kedalam lima besar untuk produktifitas sales terbaik dalam penjualan apartemen. Produktifitas tenaga penjual perbulan pada Tabel 2. Produktifitas proyek GDC (Grand Dhika City) Bekasi dapat menjual kurang lebih 1 unit setiap bulannya, tetapi masih kalah produktif dengan proyek milik PP Properti yaitu GKL - Barclay. GKL Barclay dapat menjual setidaknya 2 produk perbulan. Mardhika Park Tambun juga masuk kedalam 5 besar untuk produktifitas tenaga penjual. Mardhika Park merupaka produk apartemen FLPP (Fasilitas Likuiditas Pembiayaan Perumahaan), segmentasi apartemen Mardhika Park adalah MBR (Masyarakat Berpenghasilan Rendah). APP mempunyai keunggulan didalam pembangunan produk perumahan tapak, dimana produk perumahan yang ada di Jabodetabek tidak mengalami masalah dalam penjualan dan pengembangannya yang terus berlanjut. Sarwono (2017) menyebutkan bahwa industri properti khususnya perumahan masih menjadi pilihan utama bagi para masyarakat baik itu generasi X sampai milenial sebagai tempat tinggal utama.

\section{Key Success Factor}

Dalam suatu nilai mata rantai produk, perlu diketahui faktor-faktor yang merupaka kunci keberhasilan atau disebut juga faktor kritis terhadap kelangsung proses bisnis. Setiap perusahaan yang satu dan yang lainnya mempunyai KSF (Key Succes Factor) yang berbeda sehingga jajaran manajemen harus bisa menentukan KSF perusahaannya sendiri (Wulandari, 2017). Pribadi (1995) dalam penelitiannya membagi KSF bagi bisnis properti kedalam 3 golongan yaitu operasional, marketing dan manajemen risiko (Tabel 3). Sejalan degan Pribadi, Pefindo (Pemeringkat Efek Indonesia) (2017) juga mengelompokan KSF dibidang properti menjadi 4 bagian yaitu marketing, kualitas aset dalam hal ini adalah lahan yang dimiliki baik itu yang sudah dibangun atau belum, operasional, dan manajemen strategi proyek. Identifikasi KSF yang tepat dapat memudahkan perusahaan mengambil keputusan serta menentukan variabel mana saja yang penting, yang dapat meningkatkan kualitas serta daya saing perusahaan dalam mencapai keunggulan kompetitif (Indriatiningtias, 2010).

Tabel 2. Produktivitas tenaga penjual perbulan

\begin{tabular}{|c|c|c|c|c|}
\hline Nama Proyek & $\begin{array}{c}\text { Jumlah } \\
\text { Tenaga } \\
\text { Penjual (a) }\end{array}$ & $\begin{array}{c}\text { Rata - Rata Penjualan } \\
\text { Perbulan Dari Awal } \\
\text { Berdiri (b) }\end{array}$ & $\begin{array}{c}\text { Monthly Sales } \\
\text { Productivity } \\
\text { Ratio (b/a) } \\
\end{array}$ & Developer \\
\hline GKL - Barclay & 17 & 42 & 2,45 & PP Property \\
\hline Trans Park Juanda Tower 1 & 10 & 23 & 2,29 & PP Property \\
\hline GDC Bekasi & 11 & 21 & 1,91 & Adhi Persada Properti \\
\hline Wismaya Residence & 20 & 38 & 1,88 & Langgeng Makmur Properti \\
\hline GKL - Victoria & 18 & 32 & 1,77 & Summarecon \\
\hline Mardhika Park Tambun & 15 & 25 & 1,64 & Adhi Persada Properti \\
\hline Kota Swarna Bumi & 8 & 12 & 1,55 & PP Property \\
\hline Grand Icon Caman & 6 & 8 & 1,40 & Patraland \\
\hline Gateway Park Tower 1 & 28 & 39 & 1,40 & Adhi Persada Properti \\
\hline GKL - Emerald & 35 & 49 & 1,40 & Trans Properti \\
\hline Tamansari Urbano & 20 & 28 & 1,38 & Adhi Persada Properti \\
\hline Eastern Green & 15 & 20 & 1,36 & Adhi Commuter Properti \\
\hline The Springlake Summarecon & 30 & 38 & 1,25 & Adhi Persada Properti \\
\hline The Conexio City & 14 & 17 & 1,21 & Urban Jakarta Property \\
\hline GDCl Jatiwarna Arlington & 10 & 11 & 1,10 & Patraland \\
\hline GDCl Jatiwarna Emerald & 10 & 11 & 1,06 & Kopelland \\
\hline Tamansari Iswara & 18 & 15 & 0,86 & Adhi Persada Properti \\
\hline Urban Sky & 20 & 17 & 0,85 & Mitra Graha Andalan \\
\hline Cikunir Junction & 8 & 7 & 0,83 & Megakarya Makmur \\
\hline
\end{tabular}


Tabel 3. KSF bisnis properti

\begin{tabular}{ll}
\hline $\begin{array}{l}\text { Area Key Success } \\
\text { Factor }\end{array}$ & Key Success Factor \\
\hline Marketing & 1. Aktitas penjualan \\
& 2. Aktifitas promosi \\
& 3. Kualitas SDM \\
Operasional & 1. Perencaan anggaran dan biaya \\
& 2. Kualitas SDM \\
& 3. Pemanfaatan Teknologi \\
Kualitas Aset & 1. Analisa kualitas aset \\
& 2. Pemanfaatan aset \\
Manajemen Strategi & 1. Pengembangan lahan \\
& 2. Riset dan analisa lahan \\
\hline
\end{tabular}

\section{Business Model Canvas}

Tahapan selanjutnya setelah dilakukan identifikasi kondisi setiap elemen model bisnis kanvas saat ini adalah melakukan pemetaan terhadap kekuatan, kelemahan, ancaman dan peluang dari setiap elemen BMC APP. Gambaran kondisi BMC Eksisting APP selengkapnya pada Gambar 3.

\section{Analisis SWOT Business Model Canvas}

Hasil dari identifikasi SWOT tiap elemen BMC digunakan untuk perancangan model bisnis baru yang akan dijalankan APP di masa depan. Hasil identifikasi SWOT kesembilan elemen BMC dilihat pada Tabel 4.

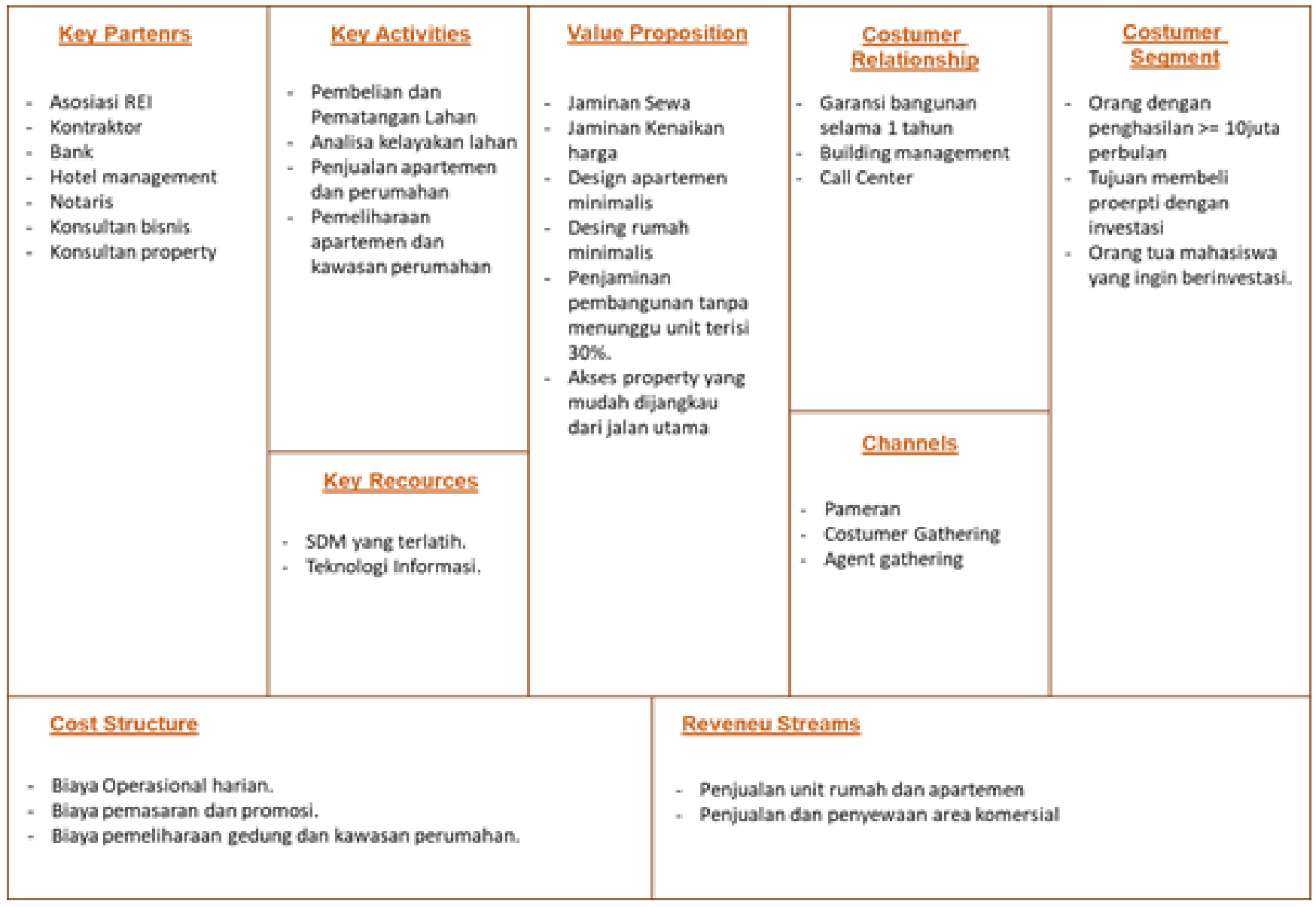

Gambar 3. Kondisi BMC Eksisting APP 
Tabel 5. Analisis SWOT Business Model Canvas

\begin{tabular}{|c|c|c|c|c|}
\hline Blok Elemen & Kekuatan & Kelemahan & Peluang & Ancaman \\
\hline $\begin{array}{l}\text { Costumer } \\
\text { Segment }\end{array}$ & $\begin{array}{l}\text { Membidik pembeli } \\
\text { dari semua kalangan }\end{array}$ & $\begin{array}{l}\text { Segmentasi terlalu } \\
\text { umum }\end{array}$ & $\begin{array}{l}\text { Segmen pelanggan dapat } \\
\text { dikerucutkan lebih detail }\end{array}$ & $\begin{array}{l}\text { Persaingan di segmen } \\
\text { tersebut semakin ketat }\end{array}$ \\
\hline $\begin{array}{l}\text { Costumer } \\
\text { Relationship }\end{array}$ & $\begin{array}{l}\text { Kualitas bangunan } \\
\text { terjamin }\end{array}$ & $\begin{array}{l}\text { Timbuk biaya } \\
\text { pemeliharaan yang } \\
\text { terkesan mendadak }\end{array}$ & $\begin{array}{l}\text { Mengembangkan cara lain } \\
\text { untuk menjalin hubungan } \\
\text { baik dengan pelanggan } \\
\text { Pemanfaatan social media } \\
\text { dan Informasi teknologi }\end{array}$ & $\begin{array}{l}\text { Pesaing menerapkan } \\
\text { cara yang sama }\end{array}$ \\
\hline Channels & $\begin{array}{l}\text { Jangkauan pasar } \\
\text { cukup luas karena } \\
\text { jaringan cukup umum }\end{array}$ & $\begin{array}{l}\text { Kurang jelas sasaran } \\
\text { pasarnya }\end{array}$ & $\begin{array}{l}\text { Membuka kesempatan } \\
\text { untuk tenaga penjual lepas } \\
\text { (freelance) } \\
\text { Pengembangan channels ke } \\
\text { perusahaan BUMN lain }\end{array}$ & $\begin{array}{l}\text { Kesamaan channels } \\
\text { dengan pesaing }\end{array}$ \\
\hline $\begin{array}{l}\text { Value } \\
\text { Proposition }\end{array}$ & $\begin{array}{l}\text { Value yang dipunya } \\
\text { cukup detail }\end{array}$ & $\begin{array}{l}\text { Pembiayaan akan } \\
\text { cukup besar karena } \\
\text { apartemen yang } \\
\text { dibangun tidak } \\
\text { menunggu unit terjual } \\
30 \%\end{array}$ & $\begin{array}{l}\text { Pengembangan nilai tambah } \\
\text { lainnya karena mempunyai } \\
\text { hak untuk mendirikan } \\
\text { bangunan di jalur LRT } \\
\text { dan juga pionir apartemen } \\
\text { kampus }\end{array}$ & $\begin{array}{l}\text { Pesaing mampu } \\
\text { menciptakan value } \\
\text { yang lebih menarik }\end{array}$ \\
\hline Key activities & $\begin{array}{l}\text { Kegiatan sudah } \\
\text { sistematis }\end{array}$ & $\begin{array}{l}\text { Tidak adanya } \\
\text { manajemen risiko } \\
\text { dalam kegiatan } \\
\text { pra, pasca dan saat } \\
\text { konstruksi }\end{array}$ & $\begin{array}{l}\text { Pengembangan aktivitas } \\
\text { laing yang dapat } \\
\text { meningkatkan daya saing } \\
\text { perusahaan }\end{array}$ & $\begin{array}{l}\text { Aktivitas sama dengan } \\
\text { pesaing lainnya }\end{array}$ \\
\hline Key Resources & $\begin{array}{l}\text { Sumberdaya yang } \\
\text { mendukung proses } \\
\text { bisnis }\end{array}$ & $\begin{array}{l}\text { Kurangnya } \\
\text { pengawasan SOP }\end{array}$ & $\begin{array}{l}\text { Pelatihan dan sertifikasi } \\
\text { kepada SDM }\end{array}$ & \\
\hline Key Partners & $\begin{array}{l}\text { Daftar rekanan sudah } \\
\text { cukup jelas dan detail }\end{array}$ & $\begin{array}{l}\text { Birokrasi cukup sulit } \\
\text { terutama dengan } \\
\text { partner yang berkaitan } \\
\text { dengan pemerintahan }\end{array}$ & $\begin{array}{l}\text { Terbukanya program } \\
\text { kemitraan dengan pihak } \\
\text { lain dengan memanfaatkan } \\
\text { program Sinergi BUMN }\end{array}$ & $\begin{array}{l}\text { Kebocoran data ke } \\
\text { pesaing lain melalui } \\
\text { partner yang sudah } \\
\text { bekerja sama. }\end{array}$ \\
\hline Cost Structure & $\begin{array}{l}\text { Biaya sudah } \\
\text { mencakup proses } \\
\text { bisinis sehari - hari }\end{array}$ & $\begin{array}{l}\text { Penyusunan RAB } \\
\text { (Rencana anggaran } \\
\text { biaya) yang kurang } \\
\text { mendetail }\end{array}$ & $\begin{array}{l}\text { Pemanfaatan teknologi } \\
\text { informasi untuk optimalisasi } \\
\text { biaya }\end{array}$ & $\begin{array}{l}\text { Timbul biaya lainnya } \\
\text { yang berkaitan untuk } \\
\text { meningkatkan daya } \\
\text { saing }\end{array}$ \\
\hline $\begin{array}{l}\text { Reveneu } \\
\text { Streams }\end{array}$ & $\begin{array}{l}\text { Biaya yang masuk } \\
\text { jelas pencatatan dan } \\
\text { asalnya }\end{array}$ & $\begin{array}{l}\text { Pemasukan yang } \\
\text { cenderung fluktuatif }\end{array}$ & $\begin{array}{l}\text { Adanya potensi revenue } \\
\text { lain dari penyewaan atau } \\
\text { penjualan area komersial }\end{array}$ & $\begin{array}{l}\text { Tertahannya uang } \\
\text { masuk dari konsumen } \\
\text { karena keterlambatan } \\
\text { pembayaran }\end{array}$ \\
\hline
\end{tabular}

\section{Perancangan Model Bisnis Baru}

Berdasarkan hasil analisis yang telah dilakukan maka terbentuknya BMC yang baru. Gambaran kondisi BMC perbaikan APP selengkapnya pada Gambar 4. Hasil analisis BMC dihasilkan beberapa strategi alternatif untuk APP sebagai berikut:

\section{Strategi pemasaran dan penjualan}

Mengerucutkan lagi segmentasi pasar yang diincar oleh APP. Segmentasi yang ada saat ini sangat umum dan biasa diimplementasikan oleh pengembang atau developer pada umumnya. Skema penjualan apartemen yang dilakukan oleh APP harus lebih menekankan kearah investasi untuk penjualan apartemen. APP sudah mempunyai unit usaha yang bernama Appartel, yaitu dengan cara menyewakan unit konsumen yang sudah terjual dan dikelola langsung oleh APP sendiri untuk meminimalisir kerusakan unit dan menambah kepercayaan konsumen untuk menyewakan unitnya. Strategi pemasaran lainnya adalah melalui media social, dimana pemanfaatan media social harus dimaksimalkan oleh APP mengingat dimasa sekarang lebih dikenal sebagai IOT (Internet of Things). Pemanfaatan media sosial bisa dilakukan dengan banyak cara mulai dari durasi update social media yang cukup sering dan mengajak orang untuk berpartisipasi 
Analisa Risiko

Manajemen risiko merupakan pendekatan yang dilakukan terhadap risiko yaitu dengan memahami, mengidentifikasi dan mengevaluasi risiko suatu proyek. Kemudian mempertimbangkan apa yang akan dilakukan terhadap dampak yang ditimbulkan dan kemungkinan pengalihan risiko kepada pihak lain atau mengurangi risiko yang terjadi (Labombang, 2016). Proyek yang sudah berjalan sampai saat ini juga harus melakukan manajemen risiko baik itu dalam pemasaran, penjualan, operasional, penunjukan konstruksi, dll. Manajemen risiko bertujuan bukan untuk menghindari masalah tetapi lebih kepada pemaparan risiko yang muncul dan mitigasi apa yang dapat dilakukan untuk menanggulangi risiko tersebut.

\section{Market Research}

Market research dilakukan untuk menganalisis lahan yang berpotensi akan dikembangkan oleh APP. Ruang lingkup market research yang perlu jangkau adalah memetakan analisis makro daerah baik itu secara kecamatan, kota/kabupaten, sampai dengan provinsi. Market research yang ada akan menggambarkan produk properti apa yang cocok untuk dikembangkan didaerah tersebut berikut dengan segmentasi pasarnya, cara pemasarannya, fasilitas pelengkap apa yang cocok untuk menunjang penjualan produk properti yang ada di daerah tersebut sampai kepada rencana jangka panjang dalam pengembangan proyek tersebut

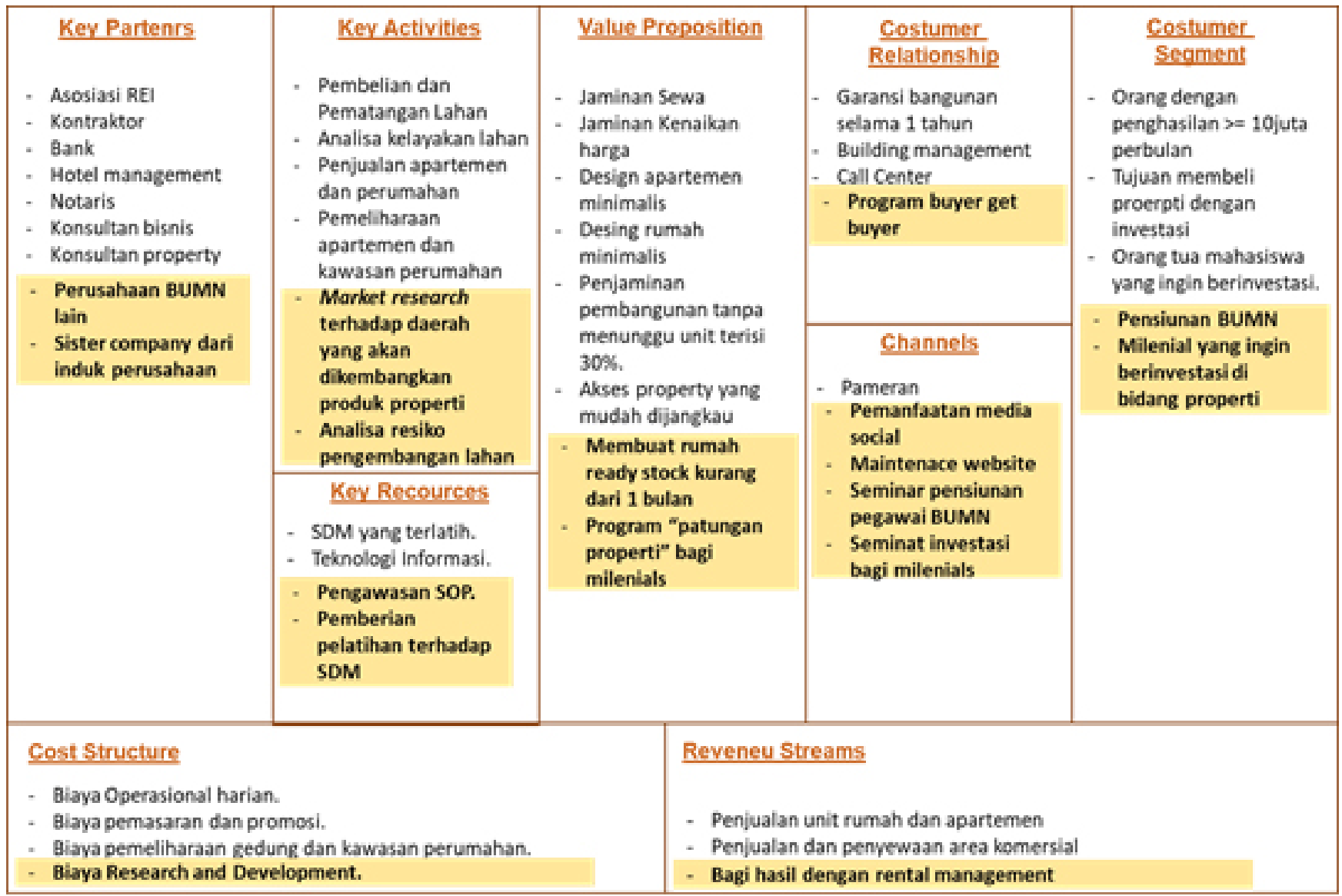

Gambar 4. Kondisi BMC perbaikan APP 


\section{Strategi fokus produk}

PT. Adhi Persada Properti (APP) juga sudah berpengalaman dalam mengembangkan perumahan terbukti dari proyek Graha Kalimas 1 dan 2 di Bekasi yang sold out dalam waktu dua tahun, Taman Melati Sawangan di depok yang terjual habis juga dalam dua tahun dan proyek perumahan terbaru yang terletak di Pakansari Cibinong, yaitu The Anggana Village yang tahap satunya terjual habis dalam waktu kurang dari lima bulan di tahun 2018 yang pada saat itu terjadi penurunan penjualan pada produk apartemen. Fokus kepada perumahan juga mendukung program sejuta rumah yang dicanangkan oleh pemerintah selain itu juga upaya dalam mengurangi Backlog perumahan yang cukup tinggi di Indonesia. Data dari Kemen PUPR (Kementrian Pekerjaan Umum dan Perumahan Rakyat Indonesia) berdasarkan data sensus tahun 2010 dan data jumlah penduduk tahun 2015 bersumber dari buku Proyeksi Penduduk Indonesia Tahun 2010 - 2015, angka backlog di Indonesia masih di angka 82,63\%. Pembangunan perumahan juga mendukung program pemerintah yang ingin membangun 5,4 juta unit rumah di tahun 2019 dan mengurangi angka backlog di tahun 2020.

\section{Implikasi Manajerial}

Implikasi manajerial yang muncul dari alternatif strategi yang dijalankan APP adalah Evaluasi pemasaran dalam segmentasi pelanggan dan perubahan strategi pemasaran yang lebih menitiberatkan pada skema investasi untuk calon pembeli dibandingkan sebagai tempat tinggal. Adanya bagian khusus yang mengawasi atau memonitoring manajemen risiko setiap proyek yang akan dikembangkan oleh APP ataupun proyek yang sedang berjalan. Pelatihan manajemen risiko juga perlu diberikan kepada pimpinan-pimpinan proyek dan manajer agar lebih peka dalam mitigasi risiko di proyek atau bagiannya masing-masing. Penambahan biaya research and development akan muncul saat bagian $\mathrm{RnD}$ dibentuk untuk melakukan market research. APP perlu menyiapkan anggaran yang tepat untuk bagian $\mathrm{RnD}$ agar dapat melakukan market research yang dapat dimanfaatkan dalam pengembangan lahan yang nantinya akan dikembangkan produk properti. APP sebaiknya lebih memfokuskan pencarian lahan untuk dikembangkan sebagai perumahan dibanding menjadi apartemen. Penjualan produk perumahan APP lebih stabil dibandingkan dengan penjualan apartemen. Produk perumahan juga mendukung program sejuta rumah yang diusung oleh pemerintah serta mengurangi backlog perumahan yang saat ini angkanya masih cukup besar.

\section{KESIMPULAN DAN SARAN}

\section{Kesimpulan}

Melalui analisis eksternal, dapat disimpulkan bahwa yang menjadi ancaman utama APP sebagai developer apartemen dan perumahan adalah dari sisi regulasi/ peraturan, situasi politik dalam negeri dan kenaikan suku bunga. Peluang yang bisa dimanfaatkan APP melalui analisis eksternal adalah tingkat daya beli masyarakat, pertumbuhan ekonomi dan kemajuan teknologi informasi. Tingkat daya beli dan pertumbuhan ekonomi lebih berpengaruh terhadap penjualan produk APP sedangkan kemajuan teknologi informasi lebih kea rah pengembangan teknologi dalam informasi produk dan fasilitas yang dapat dimanfaatkan baik itu dalam sisi operasional perusahaan maupun dalam penambahan fasilitas apartemen maupun perumahan untuk keperluan konsumen

APP belum mempunyai model bisnis spesifik dalam menjalankan bisnis. Melalui BMC identifikasi masingmasing bagian di APP dapat terpetakan dengan jelas, bagian mana yang harus di kembangkan dan mana yang dipertahankan sebagaimana adanya saat ini. Untuk mengoptimalkan BMC, APP perlu mengembangkan strategi bisnisnya di hampir setiap lini yang ada di BMC. APP juga harus bisa memanfaatkan program sinergi BUMN untuk key partnership. Promosi khusus untuk karyawan BUMN dalam membeli produk APP dan juga pemanfaatan lahan bagi perusahaan BUMN yang mempunyai lahan dan ingin menjadikannya sebagai area komersil.

Alternatif startegi yang muncul adalah segmentasi pelanggan yang lebih spesifik lagi khususnya segmentasi pensiunan BUMN, untuk pemasaran memanfaatkan medial sosial dan website resmi perusahaan sebagai sumber informasi produk, analisis risiko terhadap produk yang akan dikembangkan dan proyek yang sedang berjalan dan berfokus pada pengembangan perumahan dibandingkan mengembangkan apartemen. 


\section{Saran}

Perlu adanya evaluasi terhadap proyek yang dikembankan oleh APP dengan mempertimbangkan faktor internal dan eksternal perusahaan. Alternatif strategi dengan lebih mendetailkan lagi segmentasi pelanggan akan memudahkan APP dalam mencari niche market untuk bidang properti. Melihat track record APP yang mempunyai pengalaman membangun perumahan tapak/landed house, sebaiknya saat ini APP berfokus dalam mengembangkan perumahan karena secara psikologis orang Indonesia masih memilih perumahan dibandingkan apartemen sebagai tempat tinggal utamanya. Untuk apartemen yang sudah terbangun APP dapat mengevaluasi dari sisi pemasaran, dimana pemasaran lebih diarahkan untuk investasi daripada tempat tinggal. Penawaran investasi dalam bentuk apartemen akan lebih terlihat menarik bagi konsumen dibandingkan dijadikan sebagai tempat tinggal utama.

\section{DAFTAR PUSTAKA}

Bank Indonesia. 2017. Survei Harga Properti Residensial. Jakarta:Bank Indonesia.

[BPS] Badan Pusat Statistik. 2011. Statistik Pertumbuhan Pemukiman. Jakarta: Badan Pusat Statistik.

[BPS] Badan Pusat Statistik. 2017. Statistik Pertumbuhan Jumlah Penduduk di Indonesia. Jakarta: Badan Pusat Statistik.

[BAPPENAS] Badan Perencanaan Pembangunan Nasional. 2017. Rencana Pembangunan Jangka
Menengah Nasional (RPJMN) 2015-2019. Jakarta: Kementerian Perencanaan Pembangunan Nasional

Cassedsus MR, Ricart JE. 2010. From strategy to business model and onto tactic. Long Range Plan 43: 195-215.

Giesen E, Berman, Bell R, Blitz A. 2007. Path To Success Three Ways To Inovate Your Business Model. IBM Global Business Services 35 (6):2733.

Mufti. Prihandini. Analisis Strategi Pengembangan Bisnis Real Estate di PT. Mekar Agung Sejahtera [tesis]. Bogor: Program Magister Manajemen. Sekolah Bisnis.

Perdana AA. 2014. Analisis hubungan channel daengan costumer segment Pada BMC [tesis]. Bogor: Institut Pertanian Bogor.

Prasongko, Indra. 2016. Perkembangan properti dalam peningkatan infrastruktur transportasi Indoneisa. Jakarta.

Putri FFP, Alfanur F. 2014. Analisis Inovasi Model Bisnis mengunakan pendekatan Business Model Canvas. Jurnal Bisnis Universitas Telkom 1(2): 5-10.

Sarwono A. 2018. Faktor Penentu Pemilihan Hunian di Pulau Jawa. Jakarta.

Wardhani, W. 2015. Pengaruh Persepsi dan Preferensi Konsumen terhadap Keputusan Pembelian Hunian Green Product [tesis]. Bogor: Program Studi Magister Manajemen. Manajemen Bisnis Institut Pertanian Bogor. 